\title{
Beliefs about medication predict the misattribution of a common symptom as a medication side effect - evidence from an analogue online study
}

Running head: Misattribution of a common symptom as a medication side effect

Author Note

Monika K. Heller (Dipl Psych) and Sarah C. E. Chapman (DPhil) \& Rob Horne (PhD)

Centre for Behavioural Medicine, UCL School of Pharmacy, University College London

Correspondence concerning this article should be addressed to Professor Rob Horne, Centre for Behavioural Medicine, UCL School of Pharmacy, Tavistock Square, London WC1H; E-mail: r.horne@ucl.ac.uk 


\section{Abstract}

\section{Objective}

Some perceived medication side effects may be 'normal' symptoms that patients misattribute to the medication. Using an analogue approach, we tested if medication beliefs predict whether participants misattribute a headache as a side effect and subsequently intend to stop medication.

\section{Methods}

We recruited 690 participants, 223 reporting a past asthma diagnosis. They received information about asthma and Molair, a fictitious asthma treatment modelled on a licensed treatment (montelukast). We varied the description of efficacy and side effects (which did not include headache). Pre-exposure to this information, participants completed the Beliefs about Medicine Questionnaire (BMQ)-General and the Perceived Sensitivity to Medicines Scale (PSM), post-exposure they completed the BMQ-Specific. Participants were asked to imagine they experienced a headache while taking Molair. Finally, they rated whether the headache was a side effect (misattribution) and if they would stop taking Molair (behavioural intention).

Results

Nearly a quarter (170) of participants misattributed the headache to Molair and $69(10 \%)$ subsequently intended to stop Molair. Both outcomes were predicted by general and specific medication beliefs. Odds of misattribution $(\mathrm{m})$ and behavioural intention (i) increased with higher General Harm $(\mathrm{ORm}=1.90, \mathrm{ORi}=2.72)$, General Overuse $(\mathrm{ORm}=1.74, \mathrm{ORi}=1.56)$ and Molair Concern beliefs $(\mathrm{ORm}=1.52, \mathrm{OR}=1.78$, all $\mathrm{p}<.01)$, but decreased with General Benefit $(\mathrm{ORm}=0.72, \mathrm{OR} i=0.53)$ and Molair Necessity beliefs $(\mathrm{ORm}=0.72, \mathrm{OR} i=0.70$, all $\mathrm{p}<.05)$.

\section{Conclusion}

Symptom misattribution and subsequent intentions to stop Molair were predicted by preexposure beliefs about medicines in general and post-exposure beliefs about Molair. Patients with negative medication beliefs may be prone to misattribute symptoms and subsequently stop medication.

Key words: adherence, asthma, attribution, beliefs about medicines, nocebo, side effects 


\section{Highlights:}

- We tested if medication beliefs predict misattribution of symptoms as side effects

- Participants imagined they took a fictitious asthma medication and had a headache.

- General and specific medication beliefs predicted misattribution of the headache.

- Misattribution and negative beliefs increased intention to stop medication. 


\section{Introduction}

The prescription of a medicine is one of the most common interventions in affluent healthcare systems. Appropriate medication use is crucial to the management of most long-term conditions that account for the majority of health spending (1). But, the capacity of medication to improve health is compromised by adverse effects and nonadherence $(2,3)$. People who experience (and sometimes merely anticipate) side effects are prone to nonadherence $(4,5)$, and consequently less likely to experience the full benefit from their treatment, with implications for morbidity, mortality and healthcare utilization. For patients who take their medication, side effects add to the burden of disease and treatment (6), increase anxiety and reduce quality of life $(7,8)$. Problems linked to medication side effects in ambulatory (e.g. treatment changes, additional doctor visits) and non-ambulatory settings (e.g. longer hospitalization) were estimated at over $\$ 170$ billion per year in the US alone (9).

Understanding determinants of side effects therefore has implications for patients and healthcare systems. Side effects are often caused by specific pharmacological effects of medication. For example, aspirin inhibits prostaglandin pathways in the stomach, which can lead to gastric erosion (10). Psychological factors such as expectations and conditioning (11) also contribute to side effects. Around $20-25 \%$ of chemotherapy patients experience nausea or vomiting before drug administration $(12,13)$, indicating the importance of non-pharmacological factors in side effect experiences.

The misattribution of symptoms arising due to disease, everyday activities or normal bodily variations, as side effects may be another psychological process contributing to side effect reports $(14,15)$. Symptoms like dizziness, headache and fatigue are frequently reported as "side effects" by patients receiving placebo in randomized controlled trials (16-19) and are common in healthy individuals not taking medication (20-22).

In this paper we test whether cognitive representations of specific medications and pharmaceuticals in general (23-26) influence the attribution of symptoms as side effects. Specific medication beliefs are the salient beliefs influencing engagement with a specific treatment for a given condition. They are operationalised in the Necessity Concerns Framework $(27,28)$ which posits that evaluations of prescribed medicines are influenced by judgment of personal necessity for treatment relative to concerns about potential harm (29). These 
evaluations are influenced by general 'social representations' of pharmaceuticals as a class of treatment (e.g. whether pharmaceuticals are fundamentally harmful, addictive chemicals that are over-prescribed by doctors $(23,26,30)$ ), representations of the health threat (e.g. illness representations) and somatic experiences and attributions (e.g. whether a symptom is attributed to illness or medication) $(25,31,32)$. Symptom experiences and attributions are therefore a key determinant of how we think about and act upon illnesses (33-35). Medication beliefs have been linked to side effect reports in prospective clinical samples with rheumatoid arthritis (36), depression (37), and HIV/AIDS (38). A tendency for individuals with negative beliefs about medicine to attribute everyday 'normal' symptoms to their medication could contribute to these associations.

In this study, we asked participants to imagine taking a fictitious asthma medication and then experiencing a headache (not listed as a side effect of the medication). We probed whether participants attributed the headache as a side effect and subsequently intended to stop the medication. Although this was an analogue study, we wanted to make the scenario presented as concrete and believable to participants as possible. We therefore chose a common disease, asthma (39), so that we were could recruit participants online who either had asthma or were familiar with it. Likewise, we chose headache, a common 'everyday' symptom and side effect $(22,40,41)$ to probe symptom attribution. In addition, side effects and side effect-related discontinuation of asthma medication, and headaches to placebo have all been reported in asthma $(42,43)$. Our primary hypothesis was that participants with negative medication beliefs would be more likely to: (1) Misattribute the headache symptom as a side effect and (2) subsequently intend to stop the medication.

We systematically varied information about the fictitious medication, presenting it as highly or moderately effective and having either frequent or rare side effects. We expected the variation of the patient information to influence people's specific beliefs about the medication (e.g. increased concerns for participants randomized to high side effect frequency information). We also wanted to check whether any effect of beliefs on misattribution and intention were robust across this information variation. We explored whether the hypothesized relationships were similar for participants with and without self-reported previous asthma diagnosis and persisted when controlling for negative affect as a potential confounder. Because we were measuring beliefs about a fictitious medication, we also checked that the associations between general and specific beliefs were consistent with theoretical predictions (24) and previously reported associations (30). 


\section{Method}

Data was collected in three consecutive waves. Within each wave, participants were randomised to different descriptions of the efficacy and safety of the fictitious medication. In all waves participants completed validated measures of medication beliefs and the symptom attribution vignette. Affect was assessed in wave three.

\section{Participants and Recruitment}

We included individuals over 18, with and without self-reported past asthma diagnosis. Only one response was allowed per participant (across the three waves). Participants were recruited on online job boards (e.g. Amazon MTurk, Crowd Guru, DailySurveyPanel) where subscribers complete surveys for small monetary rewards (around $\$ 0.30$ in this study), and an online research website (Psychological Research on the Net). This sampling approach has demonstrated reliability in studies of decision-making, personality and health (44-46).

\section{Materials}

\section{Asthma and Molair information}

Participants read information about asthma (see Appendix A) structured according to Leventhal's Common Sense Model of illness representations $(47,48)$. It described asthma causes (airway inflammation and sensitization), triggers (e.g. exercise, pollen), likely consequences, and asthma management (e.g. medicines and lifestyle changes) and asthma symptoms (e.g. difficulty breathing, wheezing) and their episodic nature.

Participants were randomized to one of four written patient information leaflets (PILs) of the fictitious asthma drug Molair (see Appendix B), modelled on the existing asthma medication, montelukast (49):

1) The "High Efficacy PIL" stated that Molair is highly effective ' $86.6 \%$ of patients reported a strong improvement in daytime asthma symptoms' and contained no information about the frequency of side effects.

2) The "Moderate Efficacy PIL" stated that Molair is less effective, ' $53.2 \%$ of patients reported a small improvement' and contained no information about the frequency of side effects.

3) The "Low Side Effect Frequency PIL" contained general efficacy information "Molair can be effective in preventing asthma symptoms." and stated that side effects were rare "in less than 1 in 100 people". 
4) The "High Side Effect Frequency PIL" contained general efficacy information "Molair can be effective in preventing asthma symptoms." and stated that side effects were frequent "in more than 45 out of 100 people".

All four PILs contained the same list of 8 side effects, presented in randomized order. Headache was not listed as one of Molair's side effects.

The information was in line with published montelukast efficacy data (50-52) and reported side effect rates to montelukast relative to placebo (53) (low frequency) and placebo in randomized controlled trials (54-56) (high frequency). 


\section{Measures}

\section{Symptom misattribution and behavioural intention measures}

Participants read the following scenario: "Imagine you are suffering from asthma. You have been taking one $4 \mathrm{mg}$ tablet of Molair every day for the last two weeks. At the beginning of the third week you get a headache.' They were then asked two questions:

1) Symptom misattribution:

What do you think is the most probable reason for this?" Participants had a choice between five different options (side effect of Molair, onset of a cold, eyestrain, stress, no particular reason). Symptom misattribution was defined as indicating "side effect of Molair" as most likely reason for the headache symptom.

2) Behavioural intention to stop treatment:

Participants indicated which action(s) they would take following the start of the headache (stop taking Molair, speak to a doctor or pharmacist, take over the counter painkiller, rest, other, none of the above). Participants could select as many options as they wished and could specify additional actions. Behavioural intention was operationalised as selecting "stop taking Molair".

\section{Beliefs about Medicines Questionnaire (BMQ) (26)}

Participants' beliefs about Molair were assessed with the BMQ-Specific and general beliefs about pharmaceutical medicines as a class of treatment were assessed using the BMQGeneral.

The BMQ-Specific comprises two scales assessing beliefs about the necessity of a specific treatment for controlling an illness (5 items e.g. "My health, at present depends on Molair") and concerns about potential adverse consequences of taking it (6 items e.g. "Having to take Molair worries me"). The scales are validated $(23,26)$.

The BMQ-General comprises three 4-item scales assessing views about pharmaceutical medicines as a class of treatment. The General Harm scale assesses beliefs about the degree to which medicines are essentially harmful (e.g. "Medicines do more harm than good."). The General Overuse scale assesses beliefs about whether doctors place too much emphasis and trust on medicines (e.g. "If doctors had more time with patients they would prescribe fewer medicines."). The General Benefit scale assesses beliefs about the degree to which medicines are fundamentally beneficial (e.g. "Medicines help many people live better lives.").

All BMQ items were rated on 5 -point Likert-type scales ( $1=$ strongly disagree to $5=$ strongly agree). Scale scores were computed by summing item scores within each scale and dividing it 
by the number of scale items. Higher scores indicate stronger endorsement of scale constructs (range 1-5). The internal consistency of the BMQ-Specific (Cronbach's as: Molair Necessity=.88, Molair Concerns=.84) and BMQ-General was good (Cronbach's as: General Harm $=.75$, General Overuse $=.77$ and General Benefit $=.91)$.

\section{Perceived Sensitivity to Medicines Scale (PSM)}

The PSM is a validated scale (57) which assesses beliefs about self in relation to medicines; specifically about personal sensitivity to medicines. The scale has 5 items (e.g. "My body overreacts to medicines."), which are rated on 5 point Likert-type scales (1=strongly disagree to $5=$ strongly agree). The PSM score was computed by dividing the total scale score by the number of scale items. Internal reliability was excellent (Cronbach's $\alpha=.91$ ).

\section{Measures to assess fidelity of PIL information variations (Efficacy and Side Effect VAS)}

Visual analogue scales (VAS) were included to check whether PIL variations changed perceptions of Molair. Four VAS assessed side effect perceptions (e.g. "How frequently do you think people in general develop side effects when taking Molair?" rated from $0=$ never to $100=$ always). Three VAS measured efficacy perceptions (e.g. "How effective do you think Molair is in general for the prevention of asthma symptoms?" rated from $0=$ not effective at all to $100=$ extremely effective). Mean scores were computed for both sets of VAS. Internal consistency was high for both VAS sets (Cronbach's as of .88 and .90 respectively)

\section{Positive and Negative Affect Schedule (PANAS)}

State Negative Affect was assessed with the short form of the PANAS (58) with instructions to focus on current feelings. Ten negative (e.g. distressed, upset) adjectives were rated on 5-point Likert scales ( $1=$ not at all to $5=$ extremely). State Negative Affect (State NAPANAS) scores were computed by averaging scores for all negative adjectives. Internal consistency was high (Cronbach's $\alpha=.95)$.

\section{State and Trait Anxiety Inventory (STAI)}

The STAI Form X (59) was used to measure State (State NAstAl: 20-State Negative Affect items e.g. "I am tense.") and Trait Negative Affect (Trait NA sTAI 20-items e.g. "I worry too much over something that doesn't matter."). Items were rated on 4-point Likert scales (1=almost never to $4=a l m o s t$ always). Subscale scores were computed by averaging state and trait item scores. Internal consistency for both subscales was excellent (both Cronbach's $\alpha=.91$ ). 


\section{Demographics and reported asthma diagnosis}

Participants were asked to state their gender, age, country of residence, first language and to indicate whether they had ever been diagnosed with asthma (henceforth 'reported asthma diagnosis').

\section{Procedures}

The study was exempt from REC approval as confirmed by the UCL Research Ethics Committee.

Data was collected using Qualtrics online software (60). After giving informed consent, participants completed the PANAS and STAI (wave 3 only, see Figure 1), PSM and BMQ General. Next they received information about asthma and were randomised to receive the different PILs using the computerized block randomization function in Qualtrics. The order of side effects in the PILs was determined through simple computerized randomization in Qualtrics.

After reading the information, participants completed the Efficacy and Side Effect VAS and BMQ-Specific, and brief memory tasks (reported elsewhere). Finally, they completed the symptom misattribution and behavioural intention measure, and demographic questions. After completing the study, participants received a short written debriefing statement. It took participants approximately 14 minutes to complete the study. 
Figure 1: Overview of Procedures

\begin{tabular}{|c|c|c|c|}
\hline \multirow{2}{*}{\multicolumn{2}{|c|}{$\begin{array}{l}\text { Efficacy - PIL variation } \\
\text { Wave } 1(\mathrm{~N}=\mathbf{2 0 1})\end{array}$}} & \multicolumn{2}{|c|}{$\begin{array}{c}\text { Side effect risk } \\
\text { Wave } 2(\mathrm{~N}=249) \\
\begin{array}{cc}\text { Wave } 3(\mathrm{~N}=240) \\
\text { (as Wave } 2 \text {, but with affect } \\
\text { measures) }\end{array}\end{array}$} \\
\hline & & & PANAS, STAI \\
\hline \multirow{2}{*}{\multicolumn{4}{|c|}{ PSM, BMQ-General, Asthma Information }} \\
\hline & & & \\
\hline & & $\downarrow$ & $\downarrow$ \\
\hline \multicolumn{4}{|c|}{ Randomisation to Molair PIL } \\
\hline$n=98$ & $n=103$ & $n=245$ & $\mathrm{n}=\mathbf{2 4 4}$ \\
\hline $\begin{array}{c}\text { High } \\
\text { Efficacy } \\
\text { PIL } \\
\end{array}$ & $\begin{array}{l}\text { Moderate } \\
\text { Efficacy } \\
\text { PIL }\end{array}$ & $\begin{array}{l}\text { Low Side Effect } \\
\text { Frequency } \\
\text { PIL }\end{array}$ & $\begin{array}{l}\text { High Side Effect } \\
\text { Frequency } \\
\text { PIL }\end{array}$ \\
\hline $\begin{array}{l}\text { Molair is highly } \\
\text { effective in } \\
\text { preventing } \\
\text { asthma } \\
\text { symptoms }\end{array}$ & $\begin{array}{l}\text { Molair is } \\
\text { moderately } \\
\text { effective in } \\
\text { preventing } \\
\text { asthma } \\
\text { symptoms } \\
\end{array}$ & $\begin{array}{c}\text { Molair only } \\
\text { rarely (in less } \\
\text { than } 1 \text { out of } \\
100 \text { people) } \\
\text { causes side } \\
\text { effects }\end{array}$ & $\begin{array}{c}\text { Molair } \\
\text { frequently (in } \\
\text { more than } 45 \\
\text { out of } 100 \\
\text { people) causes } \\
\text { side effects } \\
\end{array}$ \\
\hline$\downarrow$ & $\downarrow$ & $\downarrow$ & $\downarrow$ \\
\hline \multicolumn{4}{|c|}{$\begin{array}{l}\text { Efficacy and Side Effect VAS, BMQ-Specific, Symptom Misattribution and Behavioural } \\
\text { Intention Measures, Demographics and Reported Asthma Diagnosis }\end{array}$} \\
\hline
\end{tabular}

Note. PANAS=Positive and Negative Schedule; STAI=Stat Trait Anxiety Inventory; $P S M=P e r c e i v e d$ Sensitivity to Medicines Scale; BMQ=Beliefs about Medicines Questionnaire, PIL=Patient Information Leaflet, VAS=Visual Analogue Scale 


\section{Sample size and statistical analysis}

The sample size needed to detect an association between medication beliefs and symptom misattribution was calculated using GPower v3.1. An estimated odds ratio of 1.57, based on the reported association between BMQ Concern scores and side effect reports in a large US online sample (61) was used to ascertain that 251 participants were needed to detect this univariable association with $80 \%$ power and a two-tailed alpha error probability of .05 .

Two checks were conducted to assess the validity of the model. Independent t-tests assessed whether PIL variations changed Side Effect /Efficacy VAS ratings and specific medication beliefs. Associations between general and specific medication beliefs and perceived sensitivity to medicines were examined with Pearson correlations.

Univariate logistic regression, t-tests and chi-square tests were used to explore whether symptom misattribution and behavioural intention were associated with general and specific medication beliefs, affect, demographic variables, reported asthma diagnosis, and PIL variations. Hierarchical logistic regression models tested for the effect of medication beliefs on both outcomes when controlling for PIL variations, affect and demographics in the models. We also used moderation analysis to test whether the relationship between medication beliefs and both outcomes was similar for people with and without reported asthma diagnosis and across PIL variations. Results of logistic regression models are reported using odds ratios (ORs), which reflect the change in odds of the outcome associated with a 1-unit change in the predictor. ORs above 1 indicate the outcome is more likely, ORs below 1 indicate the outcome is less likely. An OR of 1.5 constitutes a small, 3.5 a medium, and 9 a large effect size (62). Classification tables and the Hosmer Lemeshow Test (HLT) assessed adequacy of model fit. 


\section{Results}

\section{Survey completion rates and data exclusions}

We obtained 782 responses. Repeated responses from the same computer $(n=26)$, responses from underage participants $(n=2)$, and responses with missing data on the two main dependent variables were excluded $(n=64)$. Medication beliefs did not differ between completers and noncompleters (ps>.05). Responses from 690 participants (wave 1=201, wave 2=249, wave $3=240$ ) were retained.

\section{Demographic characteristics and reported asthma diagnosis}

Approximately two-thirds of respondents were female and around a third reported a past asthma diagnosis. Participants were mainly US residents (all other countries $<1$ ) and native English speakers (see Table I).

\section{Main outcomes: Symptom misattribution and behavioural intention frequencies}

Around a fourth of participants $(n=170,24.6 \%)$ misattributed the headache as a side effect and $69(40.6 \%)$ of these said that they would stop taking Molair as a result. Univariate logistic regression showed that misattribution significantly increased behavioural intention to stop the treatment $(\mathrm{OR}=8.02,95 \% \mathrm{CI}[4.69,10.69], \mathrm{p}<.001)$. Frequencies of symptom misattribution were similar in the different PIL conditions $\left(X^{2}(3)=3.80, p=.29\right)$, ranging from $20.4 \%(n=21)$ in the "Moderate Efficacy PIL" condition to $28.7 \%(n=70)$ in the "High Efficacy PIL" condition. There was also no difference in behavioural intention between PIL conditions $\left(X^{2}(3)=0.37, p=.95\right)$. Participants who reported an asthma diagnosis did not differ in rates of symptom misattribution $(n=57,25.56 \%)$ and behavioural intention $(n=25,11.21 \%)$ from those who did not $(n=113$, $24.30 \%$ and $n=44,9.50 \%$ respectively; both $p>.48$ ). Symptom misattribution and behavioural intention rates were similar for men and women. We did find a significant effect of age, with older participants being less likely to attribute the headache as a side effect and subsequently intend to stop the medication (see Table II).

\section{Between group comparisons of medication beliefs and Efficacy/Side Effect VAS}

Molair Necessity was higher for participants who were randomized to the "High Efficacy" $(\mathrm{M}=3.06, \mathrm{SD}=0.78)$ compared to the "Moderate Efficacy" PIL $(\mathrm{M}=2.78, \mathrm{SD}=0.73, t(199)=2.60$, $p<.01)$. Molair Concerns were higher for participants who saw the "High Side Effect Frequency" 
$(\mathrm{M}=3.10, \mathrm{SD}=0.83)$ compared to the "Low Side Effect Frequency" PIL (M=2.90, $S D=0.83$, $t(487)=2.59, p<.01)$. All PIL variations affected Efficacy and Side Effect VAS in the expected direction: Side Effect VAS scores were higher in the "High Side Effect Frequency" than in the "Low Side Effect Frequency" PIL conditions, and Efficacy VAS scores were higher in the "High Efficacy" than in the "Moderate Efficacy" PIL condition (all $t s>6.2$, ps<.001). Independent t-tests demonstrated no significant differences between participants with and without reported asthma diagnosis in general and specific medication beliefs (ps>.05). Participants with a reported asthma diagnosis perceived themselves to be more sensitive to the effects of medicines $(M=2.72, S D=1.05)$ than those without $(M=2.47, S D=0.97 ; t(685)=3.05, p<.01)$.

\section{Inter-correlations medication belief scales}

Concerns about Molair were significantly positively correlated with individuals' perceptions of medicines as generally harmful $(r=.371)$ and over-prescribed by doctors ( $r=.382)$. Participants with stronger benefit beliefs showed reduced Molair Concerns $(r=-.101)$ and higher Molair Necessity beliefs $(r=.260)$. Perceptions of higher personal sensitivity to medicines were significantly positively correlated with beliefs that medicines are fundamentally harmful $(r=.247)$ and overprescribed ( $r=.198)$ as well as Molair Concerns $(r=.259$, all $p s<.01$, two-tailed). 
Table I: Sample characteristics

\begin{tabular}{|c|c|c|c|c|c|}
\hline & $\begin{array}{l}\text { Wave } 1 \\
\text { Efficacy } \\
\text { information } \\
\text { variation } \\
(\mathrm{N}=201)\end{array}$ & $\begin{array}{l}\text { Wave } 2 \\
\text { Side effect } \\
\text { likelihood } \\
\text { variation } \\
(\mathrm{N}=249)\end{array}$ & $\begin{array}{l}\text { Wave } 3 \\
\text { Side Effect } \\
\text { Likelihood } \\
\text { variation with } \\
\text { affect measures } \\
(\mathrm{N}=240)\end{array}$ & $\begin{array}{l}\text { Waves 1-3 } \\
\text { combined } \\
(\mathrm{N}=690)\end{array}$ & P-values \\
\hline Age in years mean (SD) & $34.8(12.6)$ & $36.2(11.6)^{a}$ & $37.27(14.2)^{c}$ & $36.16(12.8)$ & $p=.127$ \\
\hline \multicolumn{6}{|l|}{ Gender n (\%) } \\
\hline Male & $77(38.3)$ & $73(29.3)$ & $86(36.0)^{a}$ & $236(34.3)$ & $p=.106$ \\
\hline Female & $124(61.7)$ & $176(70.7)$ & $153(64.0)$ & $453(65.7)$ & \\
\hline \multicolumn{6}{|l|}{ Race n (\%) } \\
\hline White American & $124(61.7)$ & 169 (67.9) & $147(61.5)^{\mathrm{a}}$ & $440(63.9)$ & $p=.156$ \\
\hline White British/Irish & $17(8.5)$ & $20(8.0)$ & $12(5.0)$ & $49(7.1)$ & \\
\hline Black & $14(7.0)$ & $25(10.0)$ & $27(11.3)$ & $66(9.7)$ & \\
\hline $\begin{array}{l}\text { Indian/Pakistani/Banglades } \\
\text { hi }\end{array}$ & $18(9.0)$ & $11(4.4)$ & $15(6.3)$ & $44(6.4)$ & \\
\hline Other & $28(13.9)$ & $24(9.6)$ & 38 (15.9) & $90(13.1)$ & \\
\hline \multicolumn{6}{|l|}{ First Language $\mathrm{n}(\%)$} \\
\hline English & $191(95.5)^{\mathrm{a}}$ & $234(94.4)^{a}$ & $220(91.7)$ & $645(93.8)$ & $p=.226$ \\
\hline \multicolumn{6}{|l|}{ Country of residence } \\
\hline United States n (\%) & $200(99.5)$ & $226(91.9)$ & $222(94.1)$ & $648(94.9)$ & $p=.219$ \\
\hline \multicolumn{6}{|l|}{ Asthma $\mathrm{n}(\%)^{\mathrm{d}}$} \\
\hline reported diagnosis & $73(36.3)$ & $69(27.7)$ & $81(34.0)^{b}$ & $223(32.4)$ & $p=.123$ \\
\hline
\end{tabular}

Note. ${ }^{\text {a }} 1$ missing value; ${ }^{\mathrm{b}} 2$ missing values; ${ }^{\mathrm{c}} 4$ missing values; ${ }^{\mathrm{d}}$ self-reported past asthma diagnosis; $\mathrm{SD}=$ standard deviation; $\mathrm{p}$-values refer to Chi-Square tests between waves (with the exception of age: Univariate ANOVA) 


\section{Regression analyses examining the association between medication beliefs and symptom misattribution/behavioural intention}

Univariable logistic regression was used to explore whether misattribution and behavioral intention were associated with general and specific medication beliefs. People who had more negative general and specific medication beliefs were more likely to misattribute headache as a side effect and intend to stop taking Molair. General Harm, General Overuse and Molair Concerns increased the odds of symptom misattribution and behavioural intention. General Benefit and Molair Necessity reduced the odds of both outcomes. PSM was not associated symptom misattribution and behavioural intentions (see Table II).

We then constructed two hierarchical logistic regression models to test whether negative general and specific medication beliefs predicted symptom misattribution and behavioural intention when entered jointly into the model (see Table III, Figure 2). We included demographics (age, gender), asthma diagnosis and PIL variations as control variables in step 1. General medication beliefs and PSM were entered in step 2 and specific medication beliefs in step 3. In both models, age, but none of the other control variables, was significantly associated with either outcome. In the symptom misattribution model, general medication beliefs significantly improved prediction, and adding the specific medication belief block further improved prediction. In the full model, General Harm and Molair Concerns increased symptom misattribution, while Molair Necessity reduced symptom misattribution. The effect of General Overuse was significant at step 2, but not at step 3. In the behavioural intention model, both the general and specific medication belief step significantly improved prediction. In the full model, General Harm, Molair Necessity and Molair Concerns independently predicted behavioural intention. General Benefit was associated with reduced behavioural intention at step 2, but not at step 3. Both models had adequate fit as indicated by non-significant HLTs.

Using wave 3 data, we built hierarchical logistic regression models for both outcomes, controlling for negative affect in the first step and adding general and specific medication beliefs jointly in the second step. In the model predicting symptom misattribution, the affect block was not significant $\left(\left(X^{2}(3)=3.68, p=.30\right)\right.$, while step 2 (general and specific medication beliefs and PSM) improved the model considerably $\left(X^{2}(6)=13.51, p<.05\right.$; full model $\left.X^{2}(9)=17.20, p<.05\right)$. Molair Necessity was the only significant predictor of misattribution ( $\mathrm{OR}=0.55,95 \%$ $\mathrm{CI}[0.36,0.85])$. The model had adequate fit as shown by a non-significant HLT and accounted for $77.6 \%$ correct classification of cases. In the equivalent model predicting behavioural intention, the affect block $\left(X^{2}(3)=2.01, p=.57\right)$ was not significant, while the medication belief block significantly improved prediction $\left(X^{2}(6)=18.92, p<.01\right)$. Only General Harm $(\mathrm{OR}=3.79$, 
$95 \% \mathrm{Cl}[1.62,8.90])$ was a significant predictor. The full model $\left(X^{2}(9)=20.92, p<.05\right)$ had adequate fit (HLT p>.05) and accounted for $90.0 \%$ correct classification of cases.

\section{Tests for interaction effects}

Hierarchical logistic regression models predicting symptom misattribution and behavioural intention were constructed for each medication belief. In these models the medication belief, PIL variation and their interaction term were entered in consecutive steps. No significant interaction effects between PIL variations and medications beliefs were detected ( $p s>.05$ ), indicating that the relationship between medication beliefs and both outcomes was similar for participants who saw the different PILs.

A similar set of regression models was constructed to test for interaction effects between medication beliefs and reported asthma diagnosis in predicting these outcomes. In each model the medication belief (e.g. General Harm), asthma diagnosis and the interaction term (e.g. General Harm $x$ asthma diagnosis) were entered in consecutive steps. None of the interaction terms was significant ( $p s>.05$ ), indicating medication beliefs have similar effects for individuals with and without reported asthma. 
Table II: Univariate logistic regression models predicting symptom misattribution and behavioural intention to stop treatment

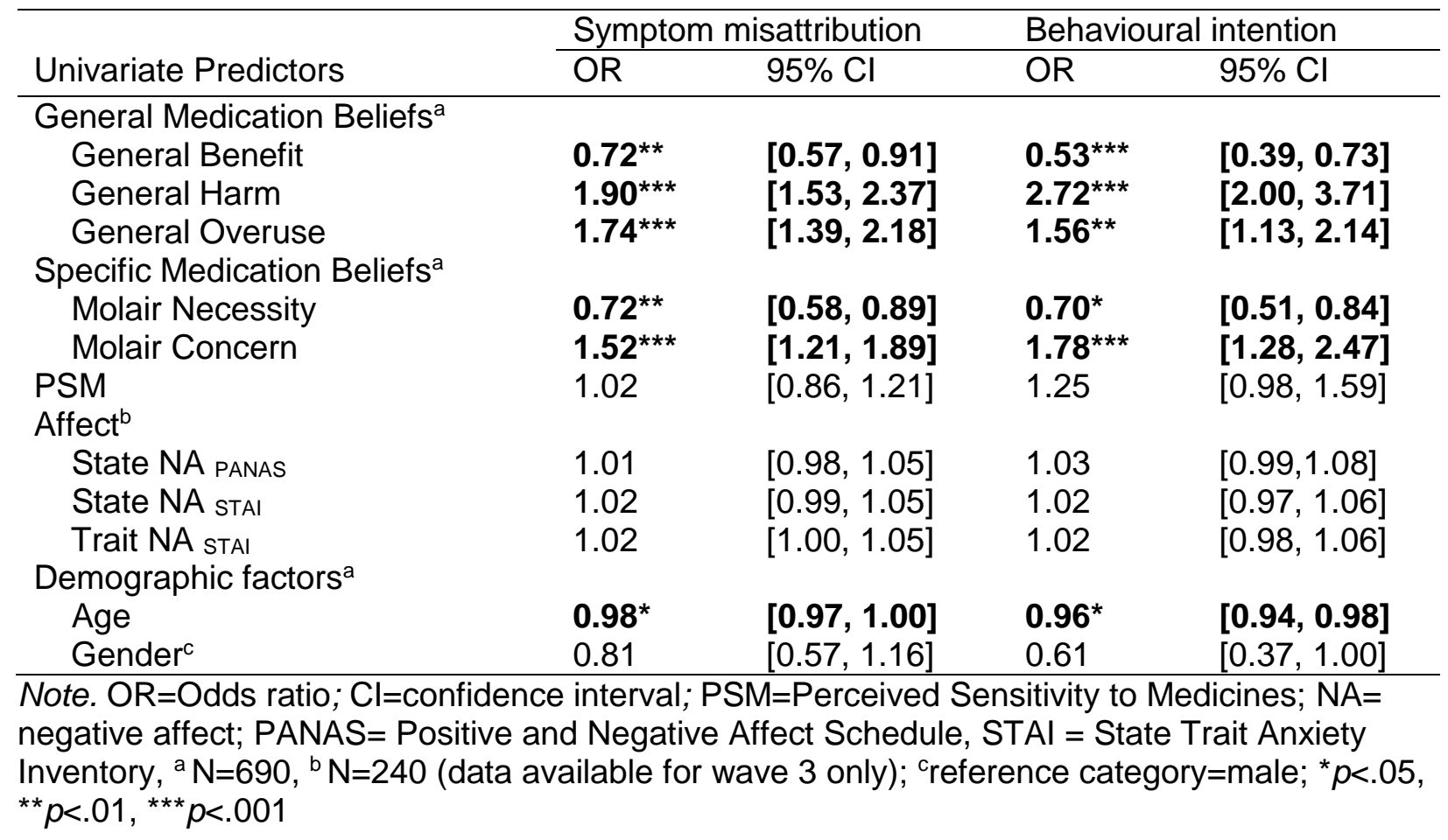


Table IV: Multivariate hierarchical logistic regression models predicting symptom misattribution and behavioural intention to stop medication ( $N=690)$

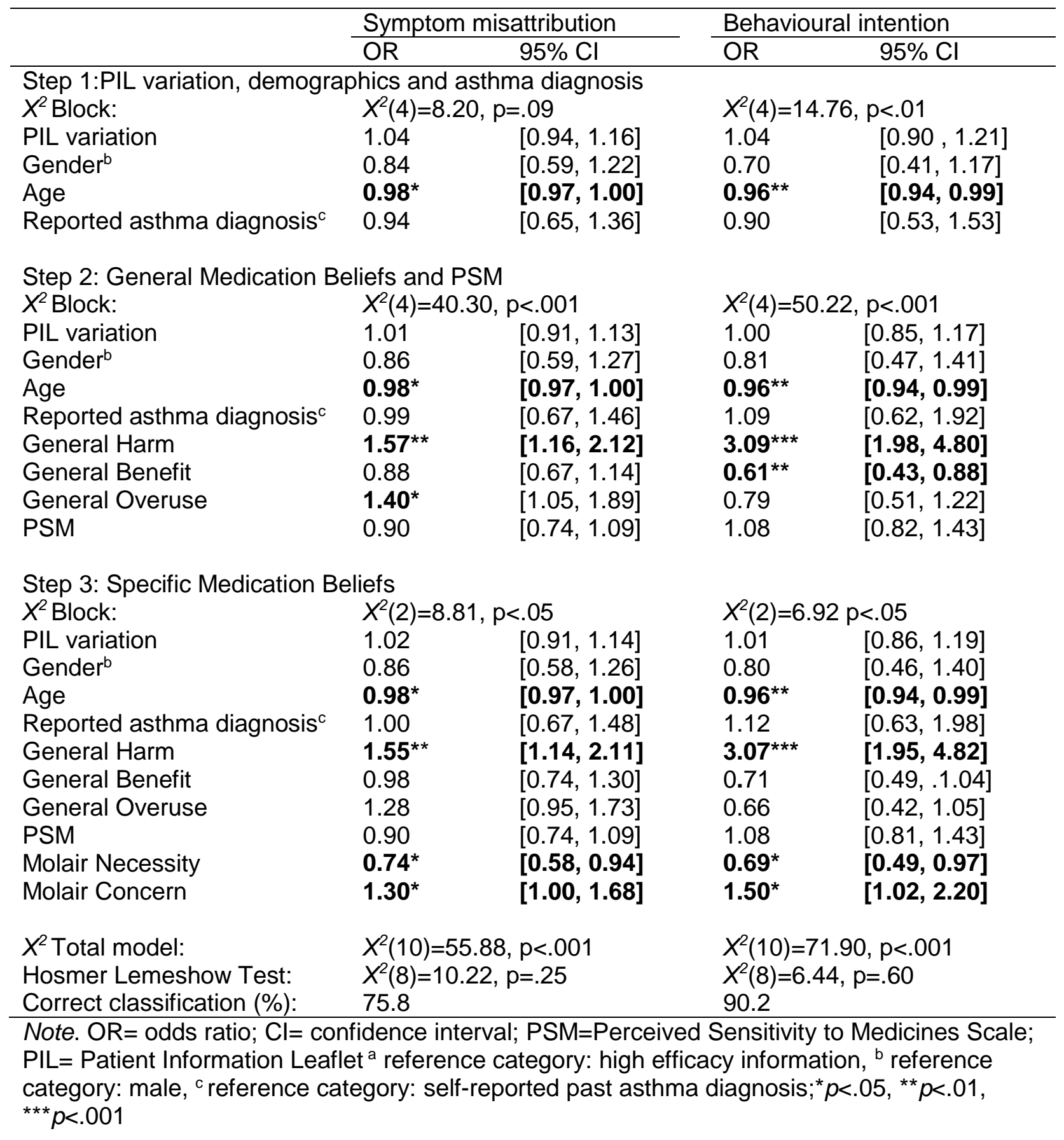


Figure 2: Hierarchical logistic regression models ${ }^{1}$ predicting symptom misattribution and behavioural intention to stop medication ( $N=690)$

- OR Symptom misattribution — $95 \% \mathrm{CI}$ Symptom misattribution

A OR Behavioural intention _.. $95 \% \mathrm{Cl}$ Behavioural intention

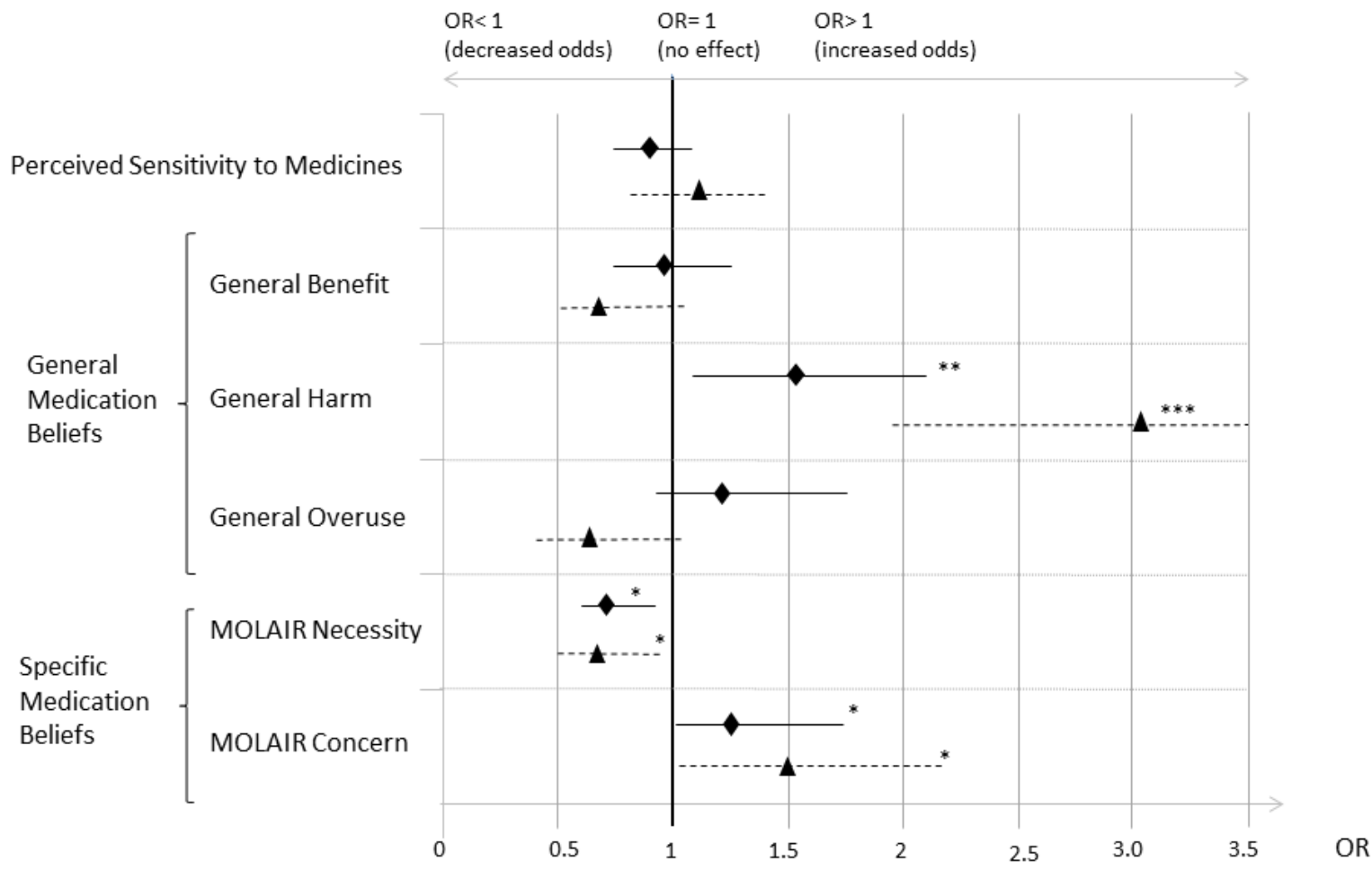


Note. ${ }^{1}$ adjusted for PIL variation, gender, age and self-reported past asthma diagnosis;

OR=Odds Ratio, $\mathrm{Cl}=95 \%$ Confidence Interval; ${ }^{*} \mathrm{p}<.05,{ }^{* *} \mathrm{p}<.01,{ }^{* * *} \mathrm{p}<.001$; 


\section{Discussion}

Using an analogue approach, we have demonstrated that misattribution of symptoms as side effects may be common (about a quarter of participants misattributed headache, not listed in the PIL, as a medication side effect) and that general and specific medication beliefs predicted symptom misattribution. Participants were more likely to misattribute headache as a side effect and intend to stop treatment if they initially believed pharmaceutical medication to be generally harmful, over-prescribed by doctors, less beneficial, and if they had stronger concerns and more doubts about need for Molair. Perceived sensitivity to medicines (PSM) was unrelated to misattribution and behavioural intention. However, correlations between PSM and both general and specific medication beliefs were consistent with our theoretical model (63). As expected from an analogue approach with a hypothetical medication, correlations between the medication belief scales were small to moderate in scale (64), yet statistically significant and in the predicted direction. The relationship between medication beliefs and symptom misattribution and behavioural intention was not affected by manipulations of side effect and efficacy descriptions in the PIL and was similar for participants with and without self-reported past asthma diagnosis. We further demonstrated that medication beliefs predicted symptom misattribution when controlling for negative affect as a potential confounder.

The associations of medication beliefs with symptom misattribution and intention to stop treatment detected in this study mirror the associations between medication beliefs, side effect reporting and adherence to medication in the clinical literature. Patients with concerns about their medication are typically less adherent, while patients with stronger beliefs in the personal necessity of medication tend to be more adherent (29). Previous studies also show that patients with stronger concerns about their medication $(36,37,61)$ and more negative beliefs about medicines in general (65) report more side effects. Misattribution of symptoms as medication side effects may help to understand part of the relationships between medication beliefs, side effect reports and adherence. Patients often experience a range of disease symptoms and sensations from normal bodily function $(14,66)$. If they have negative beliefs about medicines, they may misattribute these symptoms as side effects, thereby reinforcing negative beliefs, reducing adherence, and increasing future symptom misattribution. The size of the associations between medication beliefs and symptom misattribution/behavioural intentions in this study 
were small to moderate (64), with univariable odds ratios ranging from1.52 to 2.76. An odds ratio of 1.52 for the association of Molair Concerns and symptom misattribution indicates that for every 1 unit increase in Molair Concerns, the odds that the headache symptom is misattributed as a side effect is multiplied by 1.52 (or in other words the predicted odds are increased by $52 \%)$.

Symptom misattribution is one of several (not mutually exclusive) processes that might explain the association between negative medication beliefs and side effect reporting in clinical groups. Patients with negative beliefs about medication may monitor their body more intensively during pharmacological treatment, leading to increased side effect reporting. Several experimental studies have shown that merely attending to bodily sensations may increase the perceived intensity (67) and frequency (68) of symptoms. Medication beliefs may also influence other known nocebo mechanisms (69): patients with negative medication beliefs may form negative treatment expectations (70) and be predisposed to develop conditioned nocebo responses. Manipulations that are likely to increase concerns about other substances, e.g. warnings about chemical pollution, have been found to increase conditioned learning of somatic symptoms (71). Patients with high concerns may be more likely to learn the association between medication cues and side effect responses,

Medication beliefs are part of a complex of psychological factors that may affect side effect reporting. Individuals with high negative affect report more symptoms (72-74) and side effects $(75,76)$. Concerns about medication have also been associated with negative affect $(77)$. Negative affect may confound the relationship between medication beliefs and side effect attributions. This was not confirmed by our analysis, where the relationship between negative medication beliefs and concerns and side-effect misattribution was independent of negative effect. Other psychological factors such as Type A personality (78), somatization, depression (79), somatosensory amplification (75), pessimism (17) and alexithymia (80) (inability to identify and describe emotions) have been linked to side effect reporting to both active medication and placebo and could plausibly be associated with misattribution processes and concerns. These factors merit investigation in future studies.

There are several limitations of this analogue study using online recruitment. Our findings may not generalize to clinical settings, where patients have a medically confirmed diagnosis, comorbid conditions, take active medication and experience illness symptoms (81)). Due to the 
nature of the online sampling procedure (82) relatively few participants in the older age segment (e.g.>65) and thus less likely to have been pre-exposed to medical conditions and medication use. Participants also may not have fully understood the information they received about the hypothetical drug. Research on health literacy suggests that patients' understanding of health information is also far from perfect in general practice (83). It will however be interesting to explore whether patients who do not fully understand (or chose not to read) patient information rely more on their underlying general attitudes and beliefs when making symptom attributions. Our confidence in the external validity of the analogue approach is strengthened by findings from research in patients with medically unexplained symptoms using a similar approach to study symptom attribution (84). In the extensively used Symptom Interpretation Questionnaire (85), patients read about various common symptoms and are asked to select between different causal explanations. Patients who attribute these symptoms more to somatic and psychological factors tend to report more symptoms than patients who make normalizing attributions (85).

Despite its limitations, this study extends our understanding of side effect attributions and the role of general and specific beliefs about medicines in this process. The findings have potential clinical implications. Understanding patients' medication beliefs may help identify patients at risk of misattributing unrelated symptoms as side effects and aid the interpretation of side effect reports in RCTs and clinical practice. Medication beliefs are modifiable through cognitive-behavioural interventions (86). Potentially interventions to modify beliefs about medicines could therefore reduce non-specific side effects and related nonadherence. 
Competing Interest Statement

All authors have completed the Unified Competing Interest form at http://www.icmje.org/coi disclosure.pdf and declare that(1) $\mathrm{RH}$ has undertaken speaker engagements with honoraria with the following companies: Abbvie, Amgen, Biogen Idec, Gilead Sciences, GlaxoSmithKline, Janssen, Pfizer, Roche and Shire Pharmaceuticals. RH is a founder and share-holder of a UCL Business spin out company providing consultancy on medication-related behaviours to healthcare policy makers, providers and industry. (2) SC has undertaken speaker engagements with honoraria for Novartis and received consultancy fees from the UCL-business spin out company mentioned above (3) MH has no competing interests to report.

\section{Acknowledgements}

RH was supported by a NIHR Senior Investigator Award and by a NIHR CLAHRC (North Thames) 
Appendix A: Asthma background information

\section{What is asthma?}

Asthma is caused by inflammation of the airways. These are the small tubes, called bronchi, which carry air in and out of the lungs. If you have asthma, the bronchi will be inflamed and more sensitive than normal.

When you come into contact with something that irritates your lungs, known as a trigger, your airways become narrow, the muscles around them tighten and there is an increase in the production of sticky mucus (phlegm). This leads to symptoms including:

- difficulty breathing

- wheezing and coughing

- a tight chest

Asthma symptoms flare up from time to time and there may be no apparent reason why. However, some people find that symptoms are made worse by triggers such as exercise, fumes, and pollen. These things cause your body to produce chemical substances called leukotrienes, which cause inflammation.

1 in 12 people in the United States suffer from asthma.

\section{Treating asthma}

While there is no cure for asthma, there are a number of treatments that can help control the condition. Treatment is based on two important goals:

-relieving symptoms

-preventing future symptoms and attacks from developing

Treatment and prevention involves a combination of medicines, lifestyle advice and identifying and then avoiding potential asthma triggers. 


\section{High Efficacy/ Moderate Efficacy Patient Information Leaflet}

\section{Molair ${ }^{\circledR}$}

Molair belongs to a class of drugs called leukotriene modifiers (or leukotriene receptor antagonists). These medicines are used for the long-term control and prevention of asthma symptoms. Leukotrienes are substances made by your body that act as a trigger for an asthma attack. Blocking the action of leukotrienes helps prevent these attacks from occurring. Molair is taken in pill form.

\section{Efficacy and Side effects}

A recent large clinical trial (with 5855 asthma patients) has shown the effectiveness of Molair in adults. Following a 4-6 week treatment with Molair $86.6 \% / 53.2 \%$ percent of patients reported a strong/small improvement in day-time asthma symptoms and $88.7 \% / 56.7 \%$ a strong/small improvement in night-time asthma symptoms

Molair can be highly/moderately effective in preventing asthma symptoms, but like all medicines it may cause side effects. Please speak to your doctor if you experience any side effects while taking Molair :

- Rash

- Dizziness

- Itching

- Muscle or joint pain
- Abdominal pain

- Yellowing of the skin

- Fatigue

- Flu like symptoms 


\section{Low Side Effect Frequency / High Side Effect Frequency Patient Information Leaflet}

\section{Molair ${ }^{\circledR}$}

Molair belongs to a class of drugs called leukotriene modifiers (or leukotriene receptor antagonists). These medicines are used for the long-term control and prevention of asthma symptoms. Leukotrienes are substances made by your body that act as a trigger for an asthma attack. Blocking the action of leukotrienes helps prevent these attacks from occurring. Molair is taken in pill form.

\section{Efficacy and Side effects}

Clinical studies have shown that Molair can be effective in preventing asthma symptoms, but like all medicines it may cause side effects.

Please speak to your doctor if you experience any side effects while taking Molair:

Molair only rarely (in less than 1 in 100 people) / frequently (in more than $\mathbf{4 5}$ out of $\mathbf{1 0 0}$ people) causes the following side effects:

- Rash

- Dizziness

- Itching

- Muscle or joint pain
- Abdominal pain

- Yellowing of the skin

- Fatigue

- Flu like symptoms 


\section{Acknowledgements}

$\mathrm{MH}$ (PhD student is funded by a UCL School of Pharmacy Studentship)

SC is supported by a UCL Excellence Fellowship

$\mathrm{RH}$ is supported by an NIHR Senior Investigator Award 


\section{References}

1. Sabaté E. Adherence to long-term therapies: evidence for action: World Health Organization; 2003.

2. Boulet L-P. Perception of the role and potential side effects of inhaled corticosteroids among asthmatic patients. CHEST Journal. 1998;113:587-92.

3. Dimatteo MR, Giordani PJ, Lepper HS, Croghan TW. Patient adherence and medical treatment outcomes: a meta-analysis. Med Care. 2002;40:794-811.

4. Ammassari A, Murri R, Pezzotti P, Trotta MP, Ravasio L, De Longis P, Lo Caputo S, Narciso P, Pauluzzi S, Carosi G, Nappa S, Piano P, Izzo CM, Lichtner M, Rezza G, Monforte AD, Ippolito G, Moroni M, Wu AW, Antinori A, Ad ISG. Self-reported symptoms and medication side effects influence adherence to highly active antiretroviral therapy in persons with HIV infection. J Acquir Immune Defic Syndr. 2001;28:445-9.

5. Lambert M, Conus P, Eide P, Mass R, Karow A, Moritz S, Golks D, Naber D. Impact of present and past antipsychotic side effects on attitude toward typical antipsychotic treatment and adherence. Eur Psychiatry. 2004;19:415-22.

6. Siegel K, Schrimshaw EW, Dean L. Symptom Interpretation and Medication Adherence among Late Middle-age and Older HIV-infected Adults. J Health Psychol. 1999;4:247-57.

7. Johnson MO, Stallworth T, Neilands TB. The drugs or the disease? Causal attributions of symptoms held by HIV-positive adults on HAART. AIDS Behav. 2003;7:109-17.

8. Larsen EB, Gerlach J. Subjective experience of treatment, side-effects, mental state and quality of life in chronic schizophrenic out-patients treated with depot neuroleptics. Acta Psychiatr Scand. 1996;93:381-8.

9. Rodriguez-Monguio R, Otero MJ, Rovira J. Assessing the economic impact of adverse drug effects. Pharmacoeconomics. 2003;21:623-50.

10. Vane J, Botting R. The mechanism of action of aspirin. Thromb Res. 2003;110:255-8.

11. Benedetti F, Lanotte M, Lopiano L, Colloca L. When words are painful: unraveling the mechanisms of the nocebo effect. Neuroscience. 2007;147:260-71.

12. Roscoe JA, Hickok JT, Morrow GR. Patient expectations as predictor of chemotherapyinduced nausea. Ann Behav Med. 2000;22:121-6.

13. Zachariae R, Paulsen K, Mehlsen M, Jensen AB, Johansson A, von der Maase $H$. Anticipatory nausea: The role of individual differences related to sensory perception and autonomic reactivity. Ann Behav Med. [Article]. 2007;33:69-79.

14. Barsky AJ, Saintfort R, Rogers MP, Borus JF. Nonspecific medication side effects and the nocebo phenomenon. JAMA: the journal of the American Medical Association.

2002;287:622-7.

15. Faasse K, Petrie KJ. The nocebo effect: patient expectations and medication side effects. Postgraduate medical journal. 2013;89:540-6.

16. Pogge RC. The toxic placebo. I. Side and toxic effects reported during the administration of placebo medicine. Med Times. 1963;91:773.

17. Rief W, Avorn J, Barsky AJ. Medication-attributed adverse effects in placebo groups: implications for assessment of adverse effects. Arch Intern Med. 2006;166:155-60.

18. Rief W, Nestoriuc Y, von Lilienfeld-Toal A, Dogan I, Schreiber F, Hofmann SG, Barsky AJ, Avorn J. Differences in adverse effect reporting in placebo groups in SSRI and tricyclic antidepressant trials. Drug Saf. 2009;32:1041-56.

19. Amanzio M, Corazzini LL, Vase L, Benedetti F. A systematic review of adverse events in placebo groups of anti-migraine clinical trials. Pain. 2009;146:261-9.

20. Meyer FP, Troger U, Rohl FW. Adverse nondrug reactions: An update. Clin Pharmacol Ther. 1996;60:347-52. 
21. Khosla PP, Bajaj VK, Sharma G, Mishra KC. Background noise in healthy volunteers: A consideration in adverse drug reaction studies. Indian J Physiol Pharmacol. 1992;36:259-62.

22. Reidenberg M, Lowenthal D. Adverse nondrug reactions. N Engl J Med. 1968;279:678-

$\&$.

23. Horne R, Weinman J. Patients' beliefs about prescribed medicines and their role in adherence to treatment in chronic physical illness. J Psychosom Res. 1999;47:555-67.

24. Horne R. Representations of medication and treatment: advances in theory and measurement. Perceptions of health and illness London, UK: Harwood Academic. London, UK: Harwood Academic Publishers; 1997. p. 155-88.

25. Horne R. Treatment perceptions and self-regulation. The self-regulation of health and illness behaviour: Routledge; 2003. p. 138-53.

26. Horne R, Weinman J, Hankins M. The beliefs about medicines questionnaire: the development and evaluation of a new method for assessing the cognitive representation of medication. Psychology and health. 1999;14:1-24.

27. Clifford S, Barber N, Horne R. Understanding different beliefs held by adherers, unintentional nonadherers, and intentional nonadherers: application of the necessity-concerns framework. J Psychosom Res. 2008;64:41-6.

28. Horne R, Cooper V, Gellaitry G, Date HL, Fisher M. Patients' perceptions of highly active antiretroviral therapy in relation to treatment uptake and adherence: the utility of the necessityconcerns framework. JAIDS Journal of Acquired Immune Deficiency Syndromes. 2007;45:33441.

29. Horne R, Chapman SC, Parham R, Freemantle N, Forbes A, Cooper V. Understanding Patients' Adherence-Related Beliefs about Medicines Prescribed for Long-Term Conditions: A Meta-Analytic Review of the Necessity-Concerns Framework. PLoS One. 2013;8:e80633.

30. Horne R, Parham R, Driscoll R, Robinson A. Patients' attitudes to medicines and adherence to maintenance treatment in inflammatory bowel disease. Inflamm Bowel Dis. 2009;15:837-44.

31. Leventhal $H$, Nerenz D, Straus A. Self-regulation and the mechanisms for symptom appraisal. Symptoms, illness behavior, and help-seeking. 1982;3:55-86.

32. Leventhal $\mathrm{H}$, Brissette I, Leventhal EA. The common-sense model of self-regulation of health andillness. The self-regulation of health and illness behaviour. London: Routledge; 2003. p. 42-65.

33. Leventhal H, Nerenz D, Straus A. Self-regulation and the mechanisms for symptom appraisal. Symptoms, illness behavior, and help-seeking. 1982;3:55.

34. Baumann LJ, Cameron LD, Zimmerman RS, Leventhal H. Illness representations and matching labels with symptoms. Health Psychol. 1989;8:449-69.

35. Kolk AM, Hanewald GJ, Schagen S, Gijsbers van Wijk CM. A symptom perception approach to common physical symptoms. Soc Sci Med. 2003;57:2343-54.

36. Nestoriuc Y, Orav EJ, Liang MH, Horne R, Barsky AJ. Prediction of nonspecific side effects in rheumatoid arthritis patients by beliefs about medicines. Arthritis Care Res. 2010;62:791-9.

37. Aikens JE, Klinkman MS. Changes in patients' beliefs about their antidepressant during the acute phase of depression treatment. Gen Hosp Psychiatry. 2012;34:221-6.

38. Cooper V, Horne R. Predicting the emergence of antiretroviral therapy (ART) side effects. . Invited Symposium: The role of psychological variables 6th International Conference on HIV Treatment and Prevention Adherence; Miami, USA2011.

39. Asher MI, Montefort S, Björkstén B, Lai CK, Strachan DP, Weiland SK, Williams H, Group IPTS. Worldwide time trends in the prevalence of symptoms of asthma, allergic rhinoconjunctivitis, and eczema in childhood: ISAAC Phases One and Three repeat multicountry cross-sectional surveys. The Lancet. 2006;368:733-43. 
40. Stovner LJ, Zwart JA, Hagen K, Terwindt G, Pascual J. Epidemiology of headache in Europe. Eur J Neurol. 2006;13:333-45.

41. Tan K, Petrie KJ, Faasse K, Bolland MJ, Grey A. Unhelpful information about adverse drug reactions. BMJ. 2014;349:g5019.

42. Löfdahl C-G, Reiss TF, Leff JA, Israel E, Noonan MJ, Finn AF, Seidenberg BC, Capizzi T, Kundu S, Godard P. Randomised, placebo controlled trial of effect of a leukotriene receptor antagonist, montelukast, on tapering inhaled corticosteroids in asthmatic patients. BMJ. 1999;319:87-90.

43. Wise RA, Bartlett SJ, Brown ED, Castro M, Cohen R, Holbrook JT, Irvin CG, Rand CS, Sockrider MM, Sugar EA. Randomized trial of the effect of drug presentation on asthma outcomes: the American Lung Association Asthma Clinical Research Centers. J Allergy Clin Immunol. 2009;124:436-44. e8.

44. $\quad$ Ritter P, Lorig K, Laurent D, Matthews K. Internet versus mailed questionnaires: a randomized comparison. J Med Internet Res. 2004;6.

45. Shapiro DN, Chandler J, Mueller PA. Using Mechanical Turk to Study Clinical Populations. Clinical Psychological Science. 2013;1:213-20.

46. Buhrmester M, Kwang T, Gosling SD. Amazon's Mechanical Turk A New Source of Inexpensive, Yet High-Quality, Data? Perspect Psychol Sci. 2011;6:3-5.

47. Leventhal H, Diefenbach M, Leventhal EA. Illness cognition: using common sense to understand treatment adherence and affect cognition interactions. Cognit Ther Res. 1992;16:143-63.

48. Diefenbach $M$, Leventhal $H$. The common-sense model of illness representation: Theoretical and practical considerations. J Soc Distress Homeless. 1996;5:11-38.

49. Committee JF, Britain RPSoG. British national formulary (bnf): Pharmaceutical Press; 2012.

50. Virchow JC, Bachert C. Efficacy and safety of montelukast in adults with asthma and allergic rhinitis. Respir Med. 2006;100:1952-9.

51. Creticos PS. Treatment options for initial maintenance therapy of persistent asthma: a review of inhaled corticosteroids and leukotriene receptor antagonists. Drugs. 2003;63 Suppl 2:1-20.

52. Diamant Z, Mantzouranis E, Bjermer L. Montelukast in the treatment of asthma and beyond. Expert Rev Clin Immunol. 2009;5:639-58.

53. Singulair (montelukast) Side Effects Centre. [cited 2012 November]; Available from: http://www.rxlist.com/singulair-side-effects-drug-center.htm.

54. Mitsikostas DD, Mantonakis L, Chalarakis N. Nocebo in clinical trials for depression: A meta-analysis. Psychiatry Res. 2013.

55. Papadopoulos D, Mitsikostas DD. A meta-analytic approach to estimating nocebo effects in neuropathic pain trials. J Neurol. 2012;259:436-47.

56. Stathis P, Smpiliris M, Konitsiotis S, Mitsikostas D. Nocebo as a potential confounding factor in clinical trials for Parkinson's disease treatment: a meta-analysis. Eur J Neurol. 2013.

57. Horne R, Faasse K, Cooper V, Diefenbach MA, Leventhal H, Leventhal E, Petrie KJ. The perceived sensitivity to medicines (PSM) scale: An evaluation of validity and reliability. $\mathrm{Br} \mathrm{J}$ Health Psychol. 2013;18:18-30.

58. Mackinnon A, Jorm AF, Christensen H, Korten AE, Jacomb PA, Rodgers B. A short form of the Positive and Negative Affect Schedule: Evaluation of factorial validity and invariance across demographic variables in a community sample. Pers Individ Dif. 1999;27:405-16. 59. Spielberger C, Gorsuch R, Lushene R. Manual for the state-trait inventory. Consulting Psychologists, Palo Alto, California. 1970.

60. Qualtrics. Provo, UT, USA. 
61. Shiyanbola OO, Farris KB. Concerns and Beliefs About Medicines and Inappropriate Medications: An Internet-Based Survey on Risk Factors for Self-Reported Adverse Drug Events Among Older Adults. Am J Geriatr Pharmacother. 2010;8:245-57.

62. Vacha-Haase T, Thompson B. How to estimate and interpret various effect sizes. J Couns Psychol. 2004;51:473.

63. Horne R. Compliance, Adherence, and Concordancelmplications for Asthma Treatment. CHEST Journal. 2006;130:65S-72S.

64. $\quad$ Cohen J. Statistical power analysis for the behavioral sciences: Psychology Press; 1988. 65. Bautista RED, Gonzales W, Jain D. Factors associated with poor seizure control and increased side effects after switching to generic antiepileptic drugs. Epilepsy Res. 2011;95:15867.

66. Pennebaker JW. The Psychology of Physical Symptons: James Pennebaker; 1982.

67. Pennebaker JW, Skelton JA. Psychological parameters of physical symptoms. Personality and Social Psychology Bulletin. 1978;4:524-30.

68. Schmidt AJ, Wolfs-Takens DJ, Oosterlaan J, van den Hout MA. Psychological mechanisms in hypochondriasis: attention-induced physical symptoms without sensory stimulation. Psychother Psychosom. 1994;61:117-20.

69. Blasi ZD, Harkness E, Ernst E, Georgiou A, Kleijnen J. Influence of context effects on health outcomes: a systematic review. The Lancet. 2001;357:757-62.

70. Horne R. Patients' beliefs about treatment: the hidden determinant of treatment outcome? J Psychosom Res. 1999;47:491-5.

71. Winters W, Devriese S, Van Diest I, Nemery B, Veulemans H, Eelen P, Van de Woestijne K, Van den Bergh O. Media warnings about environmental pollution facilitate the acquisition of symptoms in response to chemical substances. Psychosom Med. 2003;65:332-8.

72. Watson D, Pennebaker JW. Health complaints, stress, and distress: exploring the central role of negative affectivity. Psychol Rev. 1989;96:234.

73. Mora PA, Halm E, Leventhal H, Ceric F. Elucidating the relationship between negative affectivity and symptoms: the role of illness-specific affective responses. Ann Behav Med. 2007;34:77-86.

74. Van Diest I, De Peuter S, Eertmans A, Bogaerts K, Victoir A, Van den Bergh O. Negative affectivity and enhanced symptom reports: Differentiating between symptoms in men and women. Soc Sci Med. 2005;61:1835-45.

75. Davis C, Ralevski E, Kennedy SH, Neitzert C. The role of personality factors in the reporting of side effect complaints to moclobemide and placebo: A study of healthy male and female volunteers. J Clin Psychopharmacol. 1995;15:347-52.

76. Foster JM, Sanderman R, van der Molen T, Mueller T, van Sonderen E. Personality influences the reporting of side effects of inhaled corticosteroids in asthma patients. J Asthma. 2008;45:664-9.

77. Gonzalez JS, Penedo FJ, Llabre MM, Durán RE, Antoni MH, Schneiderman N, Horne R. Physical symptoms, beliefs about medications, negative mood, and long-term HIV medication adherence. Ann Behav Med. 2007;34:46-55.

78. Drici MD, Raybaud F, De Lunardo C, lacono P, Gustovic P. Influence of the behaviour pattern on the nocebo response ot healthy volunteers. Br J Clin Pharmacol. 1995;39:204-6.

79. Uhlenhuth EH, Alexander PE, Dempsey GM, Jones W, Coleman BS, Swiontek AM. Medication side effects in anxious patients: Negative placebo responses? J Affect Disord. 1998;47:183-90.

80. Porcelli P, Cozzolongo R, Lanzilotta E, Giannuzzi V, Leandro G. Somatization symptoms or interferon-related adverse events? Alexithymia and somatization in somatic symptom reporting of patients with chronic hepatitis C. Psychother Psychosom. 2014;83:310-1. 
81. Shiyanbola OO, Farris KB, Urmie JM, Doucette WR. Risk factors of self-reported adverse drug events among Medicare enrollees before and after Medicare Part D. Pharm Pract (Granada). 2009;7:218-27.

82. Paolacci G, Chandler J, Ipeirotis PG. Running experiments on amazon mechanical turk. Judgment and Decision making. 2010;5:411-9.

83. Powers BJ, Trinh JV, Bosworth HB. Can this patient read and understand written health information? JAMA. 2010;304:76-84.

84. Kolk A, Hanewald G, Schagen S, Gijsbers van Wijk C. Predicting medically unexplained physical symptoms and health care utilization: a symptom-perception approach. J Psychosom Res. 2002;52:35-44.

85. Robbins JM, Kirmayer LJ. Attributions of common somatic symptoms. Psychol Med. $1991 ; 21: 1029-45$.

86. Petrie KJ, Perry K, Broadbent E, Weinman J. A text message programme designed to modify patients' illness and treatment beliefs improves self-reported adherence to asthma preventer medication. Br J Health Psychol. 2012;17:74-84. 